Document downloaded from:

http://hdl.handle.net/10251/51036

This paper must be cited as:

Rovira Soler, JA.; Martín Concepcion, PE.; Almerich Chulia, Al.; Molines Cano, JM. (2014). Class $B$ greenhouse model with double layer for Nordic European countries. Advanced Materials Research. 1065-1069:1046-1051. doi:10.4028/www.scientific.net/AMR.10651069.1046.

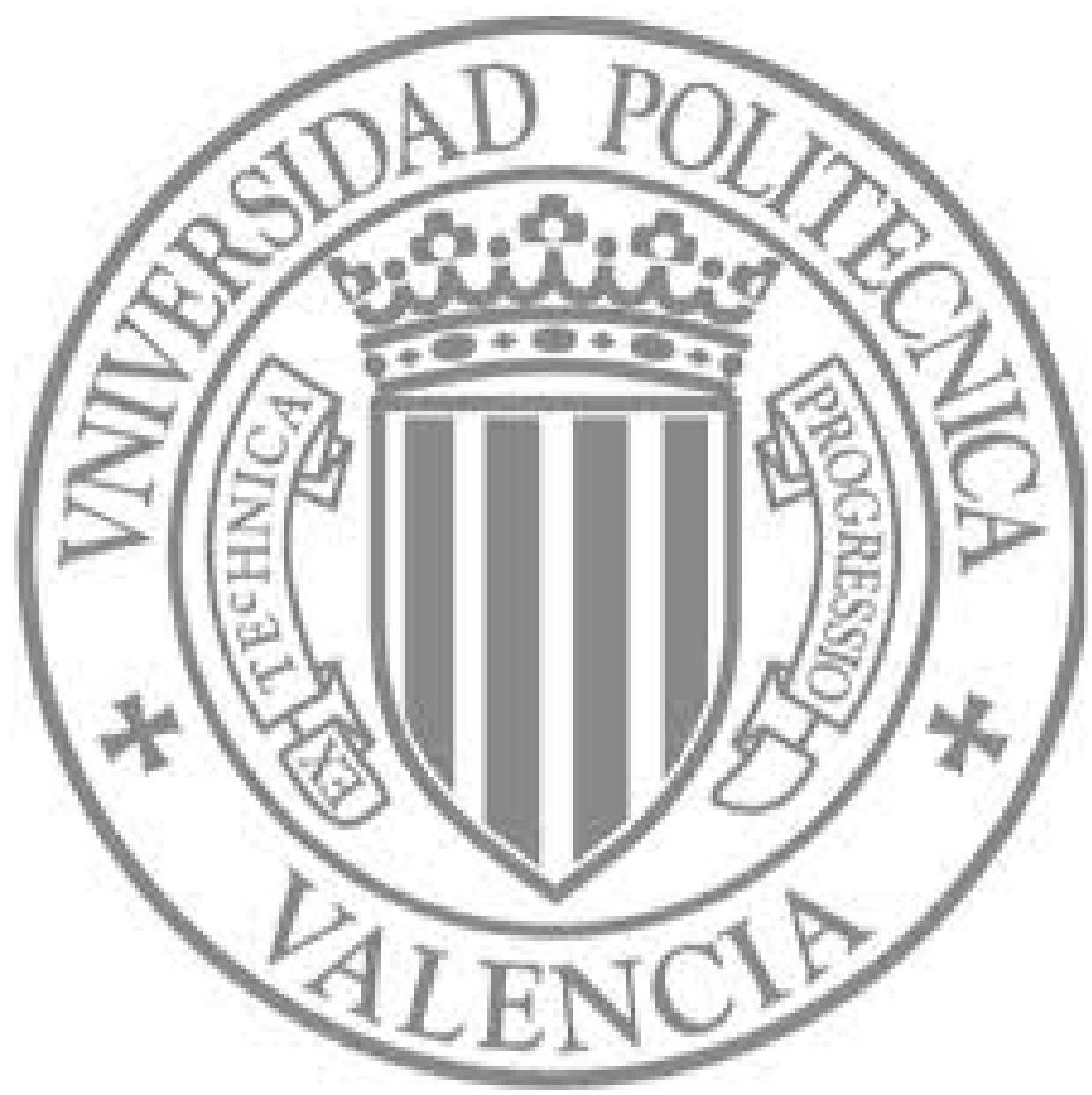

The final publication is available at

http://dx.doi.org/10.4028/www.scientific.net/AMR.1065-1069.1046

Copyright Trans Tech Publications 


\title{
Class B greenhouse model with double layer for Nordic European countries
}

\author{
Rovira Soler, Juan ${ }^{1, a}$, Martin Concepcion, Pedro ${ }^{1, b}$, Almerich Chulia, Ana ${ }^{1, c^{*}}$, \\ Molines Cano, Jose ${ }^{1, d}$ \\ ${ }^{1}$ Universitat Politècnica de València, Camino de Vera s/n, 46022 Valencia, Spain \\ ajrovira@mes.upv.es, ${ }^{b}$ pmartin@mes.upv.es, canalchu@mes.upv.es, ${ }^{d}$ molines@ctac.es,
}

Keywords: design model; environmental design; greenhouse; film covered; double layer

\begin{abstract}
This paper presents functional and structural possibilities of Class B greenhouses, which has a film covered, for areas with extreme winter temperatures and heavy snow loads, which are typical of a Class A model (glass or rigid film covered). This greenhouse study covers from its analysis in the design phase to its correct operation after construction, breaking patterns set by European standard, due to the structural design of the greenhouse, providing new possibilities for this type B, restricted to a specific geographical area so far.
\end{abstract}

\section{Introduction}

The greenhouses are defined as structures used for growing or protecting plants and crops and for optimizing the transmission of solar radiation under controlled conditions to improve the growing environment. Its dimensions allow working people inside [1]. They are designed with a low level of security in order to optimize costs. Parameters with greater relevance in the design and conception of greenhouses are temperature and radiation. The needs of these can be the same for the same crop but completely different for a warm or cold weather.

In the 90s, the increasing import and consequently the demand for greenhouses, both in Spain and in the rest of Europe, brought with it the need to draft a European standard to establish the guidelines in the design and construction of greenhouses for commercial production. Greenhouses technical committee CEN/T C284 was created (formed by technicians, companies, AENOR...) whose mission was to develop the criteria and design basis for commercial production greenhouses in Europe [2]. The CEN/T C 284 committee deals with the first draft of the EN13031-1 standard, which develops the use of greenhouses for commercial production. It is the main difference with greenhouses which permit free access of people (such as gardens, exhibitions or small home greenhouses) are safety factors (due to the continued presence of people inside) [3]. This standard is called EN13031-1 [4]. This rule classifies greenhouses according to the useful life and the type of enclosure, distinguishing two types: rigid or glass panel (Class A) or film covered (Class B). The difference of use between these covers, functionally distinct, has always been closely linked to its geographical location, specifically due to the external weather conditions and their impact on the internal microclimate. The greenhouse type A is more common in Northern European countries and they are known particularly by its glass or plastic rigid covering. On the other hand, type B greenhouses are built with cover film, also formally called Mediterranean greenhouses, because of their origin in the South of Spain (the first one of them was the greenhouse developed by Altos Hornos de Vizcaya), although quickly they were being built in other Mediterranean latitudes, such as France, Italy and Greece.

The choice of the cover has a direct influence on all parameters of the system, whether productivity, climatic or mechanical. The mechanical properties of the structure of a greenhouse are closely related to the type of material used in the cover. Because of this, the transmission of the loads to resistant structure is different. Consequently, the greenhouse design depends a lot on the physical and mechanical properties of the type of material used in the enclosure. [5]

Technology development over the years has led to significant development in type B greenhouses. The evolution of covering elements from its beginnings to modern material, more permeable to 
luminosity and with greater strength and durability, has the potential to replace the Type A (hard cover, which currently dominates northern Europe) with type B (restricted to warm areas), improving performance and lowering costs. This technological progress allows its use in locations (Poland, Russia, Ukraine...) and an improved performance which was unthinkable in 90's. However, this is not due only to better construction resources, but also to technologies that facilitate the calculation and optimize the design without forgetting compliance with structural behavior.

The covering design with two layers of film and an internal inner chamber has improved both the environmental and the typological and structural services. The air inclusion between two sheets of film gives the greenhouse a completely smooth cover, due to the absence of creases and therefore less opposition to the wind. It also promotes the sliding of newly fallen snow reducing the snow loads. All this is added, as well as improved interior comfort conditions.

This article shows the possibility of using a type of greenhouse, proper of a specific geographical area (moderate temperatures and nil or negligible snow loads), in areas with extreme winter temperatures. This paper presents structural design, results obtained from modeling and the verification of a real-studied model, once built and operating.

\section{Greenhouse design}

The most important aspects in the structural design of this greenhouse model have been conditioned by the agricultural activity to develop inside, the growing of large trees: pines and large snow loads expected for much of the year. In the design, there are no snow accumulation reductions because there is no self-contained heating. Therefore, it is considered that there is no heating installation. Under these conditions the design model is generated.

The main structural frame has an ogee-shaped (Fig. 1a). This model takes into account both economic and structural settings. Structural sections are optimized according to the constructional and functional conditions due to its location.

The greenhouse model of this design study is classified as a greenhouse Class B. It has been made by an arch steel, monospan, with a span of $25 \mathrm{~m}$ and height $10.6 \mathrm{~m}$ (Fig. 1b), each separated $2.5 \mathrm{~m}$ attached by roof purlins. Characteristic value of snow load is $0.70 \mathrm{kN} / \mathrm{m}^{2}$ and wind speed is $27 \mathrm{~m} / \mathrm{s}$ for agricultural areas. Therefore, the importance of this new model lies not only in the snow load, but also on the dimensions, proposed model has twice the usual size. Normally these greenhouses have been characterized by the moderate span of $12 \mathrm{~m}$.

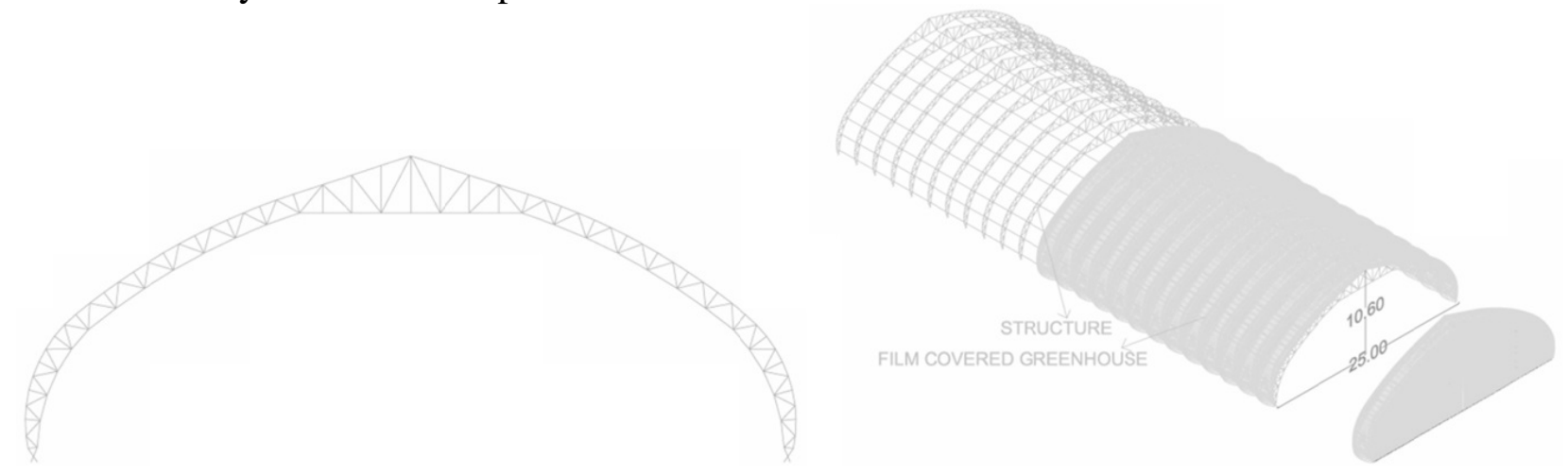

Figure 1. Design model of greenhouse.

a) monospan arc.

b) global view

On the other hand, purlins are located in inner cords, in order to prevent breakage of air chamber between the double layer of film, and thus its proper operation. Their arrangement is not random. We have analyzed behavior on the ends of Warren truss model, so the top chord of a truss is bracing and does not interfere with the operation of the enclosures.

The model is adapted to the needs of any location as long as the characteristic values of considered construction loads are not exceeded, ensuring its correct structural and thermal behavior, meeting the requirements of design which is built. 


\section{Structural analysis}

For design, analysis and verification of this structural model of greenhouse have been used first-order elastic analysis methods by structural analysis software used (SAP2000 v13). All elements of structure have been considered for the calculation: frames, joints, forming a hyperstatic set, with their geometrical and mechanical characteristics; as well as the acting loads.

Modeling of the structure has been made taking into account the geometry of the structure, with the joints generated by the intersection of the frames and other nodes created in other positions of the elements, which have been considered suitable for obtaining the necessary information.

The model also takes into account the materials used (steel), type of sections, basic assumptions, and the load combinations according to limit state design. By all the linear study was performed without considering second order effects. The model meets the requirements described in European standard for steel constructions and EN13031-1 for commercial greenhouses.

Joints. The joint design has been one of the points of greatest interest and special complication in the model considered. Its importance has been focused on the difficulty of making the splice in the encounter with the enclosure, which is composed of two sheets of film with intermediate air chamber, without breaking.

The most appropriate solution found is based on the transfer moment of each section on a set of vertical members connected along its length, with a non-uniform section. These were designed to absorb these moments, maximizing the material section, without breaking the slenderness of the structure and its low cost. Joints are performed with bolts embedded inside these elements (Fig. 2).

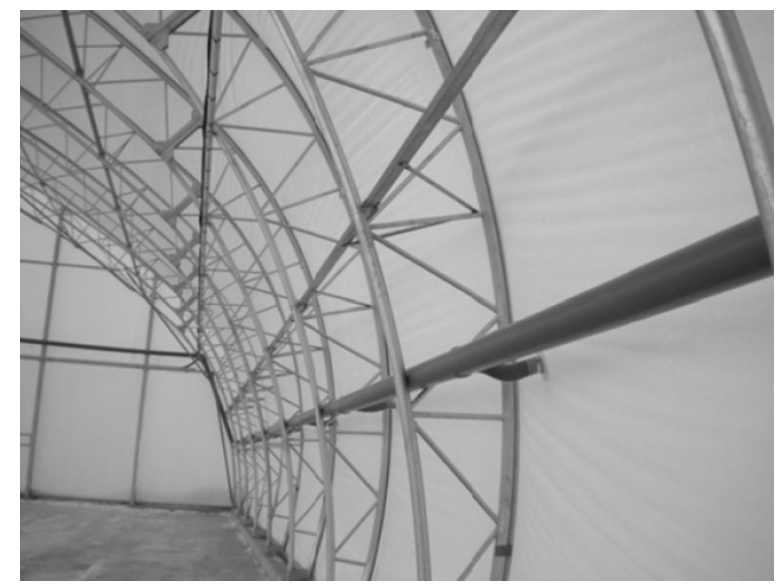

Figure 2. Design joints.

Loads. European Convention for Metallic Construction (ECMC) rule was the prelude to the current European Standard 13031-1. ECMC rule was drafted in 1987 by the Technical committee N12. It has served as a reference to define the calculation methods of wind load in steel structures and more specifically with the recommendations for the calculation of wind effects on greenhouses. [5].

Wind, crop and snow load combinations are satisfied at the same time, based upon the recommendations of ECMC and European Standard EN13031-1.

Permanent load. Permanent load is composed of structural members and covered film weights. It is important to explain that it is not considered the service used load on the installation during execution or maintenance, because of EN13031-1 does not contemplate for greenhouse commercial.

Crop load. Crop load is null because the greenhouse is dedicated to growing pines.

Wind load. Structural forms of the greenhouse are one of the key factors to be considered, due to the different influence of the wind on it. Curved roofed greenhouses are increasingly used because they offer aerodynamically efficient shapes. [6, 7]

The characteristic velocity and pressure coefficients are the most relevant factors for the calculation of wind action on this type of structure. The reference wind velocity $\left(\mathrm{v}_{\mathrm{b}}\right)$ is defined as mean wind velocity during $10 \mathrm{~min}$ at $10 \mathrm{~m}$ above ground of terrain category II. In this case, the 
reference wind velocity is $27 \mathrm{~m} / \mathrm{s}$. Wind load is calculated using the reference velocity and some coefficients.

$$
v_{d}=v_{b} \cdot c_{p e} \cdot c_{t} \cdot c_{r} \cdot c_{d} \cdot c_{p}
$$

Figure 3 shows the values obtained from the external pressure coefficients for a lateral wind.

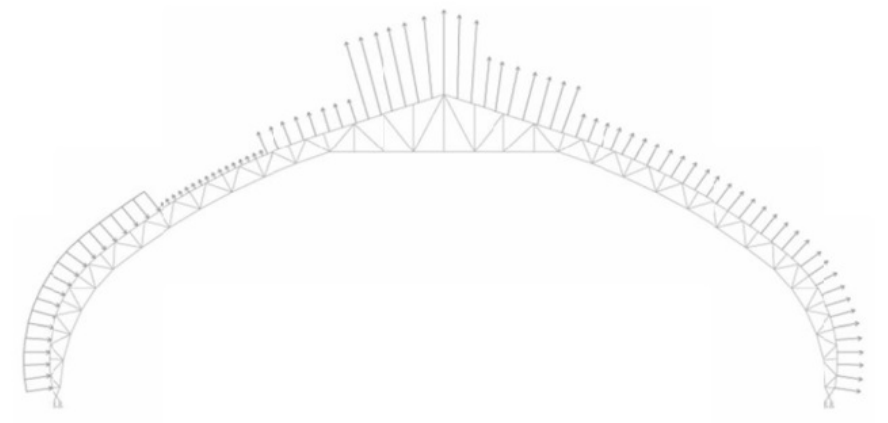

Figure 3. External pressure coefficients for lateral wind.

Snow load. Snow load is particularly relevant because of the geographical location of the greenhouse. EN1991-1 and EN13031-1 standards are taken as reference to estimate the characteristic values of snow on the greenhouse $\left(\mathrm{s}_{\mathrm{k}}\right)$. Snow load $(\mathrm{s})$ is determined for persistent situations such as:

$$
s=\mu_{i} \cdot c_{e} \cdot c_{t} \cdot s_{k}
$$

The influence of the angle in the studied model is shown in the following picture (Fig. 4a). There is an area with a pitch angle less than $60^{\circ}$, where snow accumulation is possible. And there is another area where snow cannot possibly accumulate because the angle of pitch is more than $60^{\circ}$. With this model, criteria standard for snow accumulation have been able to verify. In this case, for monospan greenhouse, these values are lower due to the characteristics of the cover (Fig. 4b). [8, 9]
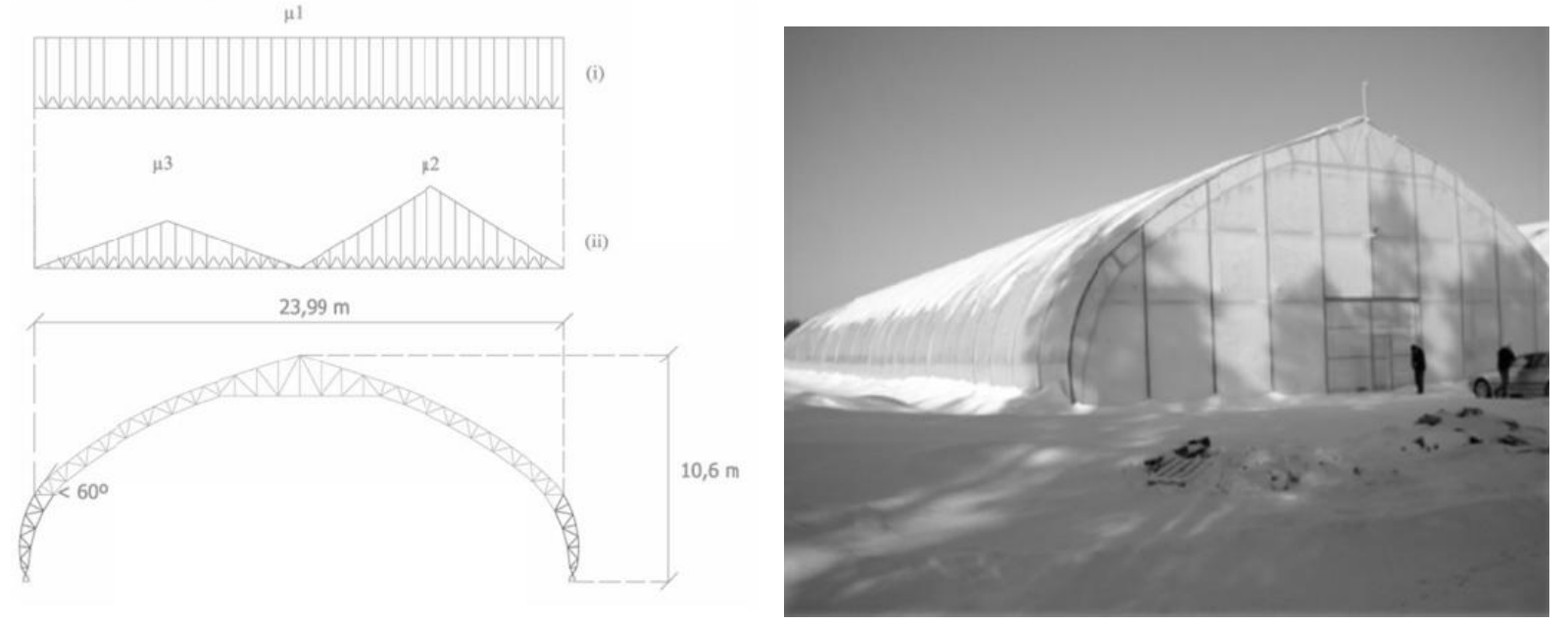

Figure 4. Snow accumulation zones:

a) Influence of the angle

b) Real

Load combinations. The structural capacity of Class B greenhouse must not be exceeded under the design values of the loads. So, all design values of loads that may occur simultaneously must be considered in combination. According to EN 13031-1, ultimate limit states must only be verified in the Class B greenhouse. 


\section{Results of structural analysis}

Eurocodes allow checking Ultimate States Limit by calculating the design values of the effect of the actions $E_{d}$ (internal force, moment, tension...) and comparing them with design value of the corresponding resistance $\mathrm{R}_{\mathrm{d}}$. The checks are performed in the most unfavorable combinations of all of possible load combinations. In this case, these have been two combinations:

- ELU1: $(\mathrm{PP}+\mathrm{W})$ : Permanent + Wind

- ELU2 / ELU3: (PP + S): Permanent + Snow (two cases)

Then, different checks performed to verify the validity of the proposed structure is shown.

Forces and stresses. Tension and compression forces resulted from these loads are presented in Table 3 for the envelope of the more unfavorable load combinations.

In addition, stresses are applied to each item is displayed in Table 3, showing the validity of the proposed model. All of them are subjected to stress, lower than the characteristic resistance of material (262 MPa).

Table 3. Elements greenhouse. More unfavorable values of axial forces

\begin{tabular}{|c|c|c|c|}
\hline & Tensile max $(\mathrm{kN})$ & Compression max $(\mathrm{kN})$ & Stress $(\mathrm{MPa})$ \\
\hline Top Chord & 41 & -63 & 210 \\
\hline Bottom Chord & 74 & -35 & 245 \\
\hline Stanchion & 5.2 & -5.6 & 72 \\
\hline Diagonal & 15.8 & -13 & 163 \\
\hline
\end{tabular}

Displacements and deflections. Although Class B greenhouses are not verified against the Serviceability Limit States (according to EN13031-1), it is recommended to know the magnitude of the deformations and displacements for greater control of the structural behavior. The most significant values for vertical deflections are obtained by gravity loads, and horizontal displacements by gravity loads along with the wind (Table 4). According to the values obtained, we test the maximum vertical deflection is less than $\mathrm{L} / 250(0.10 \mathrm{~m})$ and the maximum horizontal displacement is less than $\mathrm{H} / 150(0.07 \mathrm{~m})$. With these results, it is found that the maximum deformation/deflection considered for each case is accepted for this model with double covered film.

Table 4. Displacements and deflections

\begin{tabular}{|c|c|c|}
\hline & Vertical deflection $(\mathrm{m})$ & Horizontal displacement $(\mathrm{m})$ \\
\hline $\mathrm{PP}+\mathrm{S}$ & $1.85 \cdot 10^{-2}$ & $0.02 \cdot 10^{-2}$ \\
\hline $\mathrm{PP}+\mathrm{W}$ & $2.1 \cdot 10^{-2}$ & $4.70 \cdot 10^{-2}$ \\
\hline
\end{tabular}

\section{Conclusions}

Results show that the model is correct from the point of view of structural design. This detailed study is vital to maintain the integrity of the structure in case of strong winds, rain, snow... Design model is based on the optimization of the structural sections, so the failure of any of these elements would entail the total collapse of the structure by "domino effect".

In view of the results obtained, it can say that the proposed model is valid for its construction in latitudes where snow and wind loads described above. The model implements a solution for building Class B greenhouse in Nordic countries, which until now it was built in warm latitudes.

After the analysis of the model, one proceeds to its construction. Some excellent results and behavior consistent with the environmental conditions are obtained, as shown in the attached images. Furthermore the proposed cover with two layers of film and an internal inner camera complies with the desired expectations regarding its thermal behavior (Fig 5a, 5b).

In short, the model opens a new application for this type of greenhouse to places where construction was hitherto unthinkable, reducing its cost with respect to those used so far and optimizing the initial investment. 


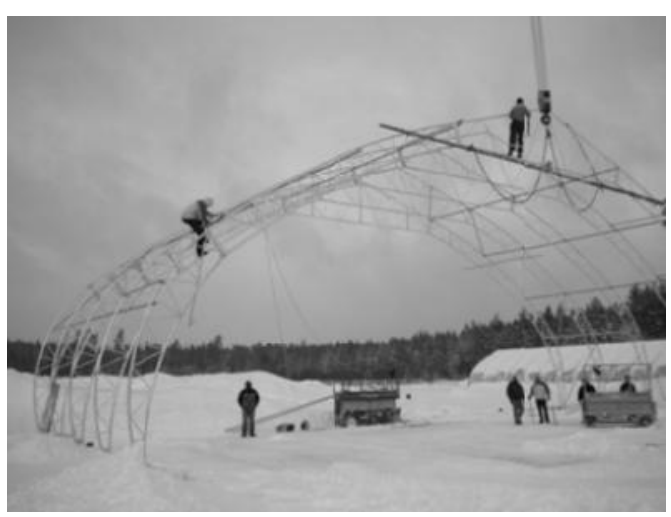

Figure 5a. Greenhouse construction.

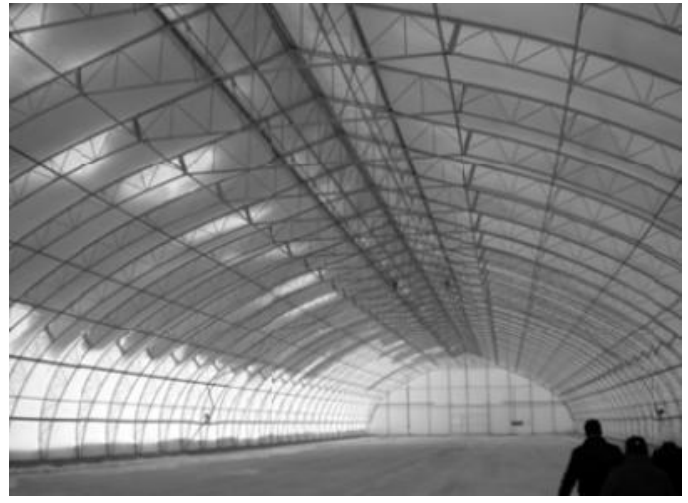

Figure 5b. Interior greenhouse.

\section{Acknowledgements}

We gratefully acknowledge INVERCA S.A for work and technical assistance, and provide data and information necessary after construction of the greenhouse.

\section{References}

[1] K. Berna. Structural analysis of greenhouse: a case study in Turkey. Building and Environment Vol. 41 (2006), p. 864-871.

[2] J. Nebot, J. Rovira, J. Garro, J. Martin, A. Aguado, A. Bonilla, A. Alonso, A. Committee technical CEN n ${ }^{\circ} 284$ (1998).

[3] J. Bosco. Horticultura. Revista de Hortaliza, Flores y Plantas Ornamentales Vol. 6. (1992).

[4] EN13031-1. Greenhouse: Design and construction - Part 1: Commercial production greenhouses (2002).

[5] P. Martin. Invernaderos de cubierta flexible: modelización de la acción del viento. Thesis. Editorial UPV (2003).

[6] O. Yekutieli, L. Dubinski, I. Kleinmann. Analysis of forces acting due to strong wind loads on structure and cover of walk-in tunnel. International Conference and British-Israeli workshop on greenhouse technologies (1997), p. 53-61.

[7] A. Mistriotis, D. Briassoulis. Numerical estimation of the internal and external aerodynamic coefficients of a tunnel greenhouse structure with openings. Computers and Electronics in Agriculture Vol. 34 (2002), p.191-205.

[8] D. Briassoulis. Mechanical design requirements for low tunnel biodegradable and conventional films. Biosystems Engineering Vol. 87 (2) (2004), p. 209-223.

[9] A. Robertson, P. Roux, J. Gratraud, G. Scarascia, S. Castellano, M. Dufresne de Virel, P. Palier. Wind pressures on permeably and impermeably-clad structures. Journal of Wind Engineering and Industrial Aerodynamics Vol. 90 (4-5) (2002), p. 461-474. 